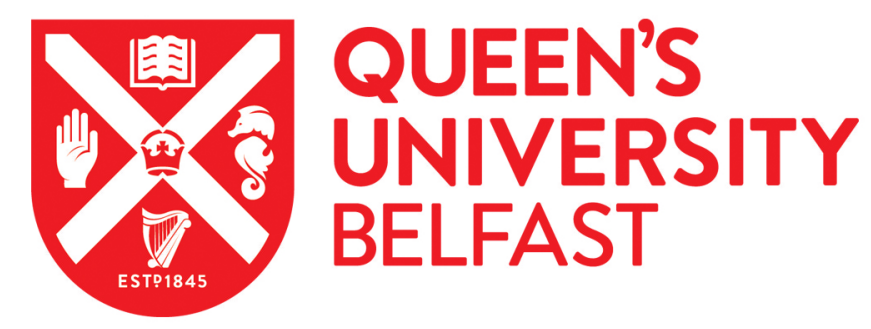

\title{
'Some Good Clean Fun': Humour, Control and Subversion in an Advertising Agency
}

Kenny, K., \& Euchler, G. (2012). 'Some Good Clean Fun': Humour, Control and Subversion in an Advertising Agency. Gender Work and Organization, 19(3), 306-323. https://doi.org/10.1111/j.1468-0432.2012.00594.x

\author{
Published in: \\ Gender Work and Organization
}

Document Version:

Peer reviewed version

Queen's University Belfast - Research Portal:

Link to publication record in Queen's University Belfast Research Portal

Publisher rights

(c) 2012 Blackwell Publishing Ltd.

This is the peer reviewed version of the following article: Kenny, K. and Euchler, G. (2012), 'Some Good Clean Fun': Humour, Control and Subversion in an Advertising Agency. Gender, Work \& Organization, 19: 306-323., which has been published in final form at doi:

10.1111/j.1468-0432.2012.00594.x. This article may be used for non-commercial purposes in accordance with Wiley Terms and Conditions for Self-Archiving.

\section{General rights}

Copyright for the publications made accessible via the Queen's University Belfast Research Portal is retained by the author(s) and / or other copyright owners and it is a condition of accessing these publications that users recognise and abide by the legal requirements associated with these rights.

Take down policy

The Research Portal is Queen's institutional repository that provides access to Queen's research output. Every effort has been made to ensure that content in the Research Portal does not infringe any person's rights, or applicable UK laws. If you discover content in the Research Portal that you believe breaches copyright or violates any law, please contact openaccess@qub.ac.uk. 


\title{
‘Some Good Clean Fun’: Humour in an Advertising Agency
}

\author{
Kate Kenny and Gordon Euchler
}

Please reference as:

Kenny, K. \& Euchler, G. (2012) '"Some Good Clean Fun": Humour, Control and Subversion in an Advertising Agency'. Gender, Work And Organization, 19(3): 306323.

The final, definitive version of this paper has been published in Gender, Work and Organization by Wiley. All rights reserved. (C) This is the accepted version, posted by the first author on the Queen's University Belfast website under the terms of the contributor agreement.

Accepted version, final publication:

http://onlinelibrary.wiley.com/doi/10.1111/j.1468-0432.2012.00594.x/abstract 


\begin{abstract}
This article explores the relation between humour and control, drawing on participant observation in an organization in which humour was central to daily life. Keys is a leading advertising agency whose staff spent an unusually large amount of time sending humorous e-mails. Examining these e-mails in some depth, we unpack the role of humour in subverting various forms of control, including gender norms and managerial authority. We find the relation between humour, control and subversion to be ambiguous. Building upon current debates in organization studies, we develop the concept of humour based on our observations at Keys. Specifically, we argue that humour is always in excess of both control and subversion, a 'nicely impossible' object that cannot be captured. This article thus contributes to theoretical approaches on organizational humour, conceptualizing the concept of 'newness' through Judith Butler's re-reading of Derridean différance and the Lacanian Real. In addition, we contribute a novel empirical account of the study of e-mail list humour in a contemporary advertising firm.
\end{abstract}

Keywords: humour, organization, e-mail, Butler, control

\title{
Introduction
}

This article is based on participant observation at Keys, a young, trendy organization located in a run-down but increasingly fashionable part of a large European city. Keys is in the business of cutting edge creative work: ideas take primacy. The working day involves much hanging out on bean-bags chatting to colleagues, or trying to beat the high score on the office pinball machine. Most of the team are comfortable with digital technology, graphic design and the Internet. At Keys, a lot of time is spent sending group e-mails to one's colleagues, e-mails that contain jokes, weird images and links to online videos: always new, always fresh, always funny. This 'funnyness' forms the focus of this article: at Keys, a particular flavour of humour persisted in the e-mails that circulated. At first, there appeared to be few boundaries: jokes could be politically incorrect: sexist, racist, homophobic and potentially hurtful, as long as they were new and they made people laugh. On closer examination, this boundaryless humour appeared inscribed by very specific forms of control, including gender stereotypes and managerial authority. 
Beginning this investigation, it is helpful to examine what has already been written on the interaction of humour and control, a growing area of interest in organization studies (Bolton and Houlihan, 2009; Fineman, 2003). For the sake of presentation, we isolate two approaches to the topic for discussion: the first focuses on the potential for humour to subvert forms of dominance in organizations and the second advocates humour as an important means of asserting control in the workplace. We find that presenting the two contradictory approaches side by side is useful: it highlights the inescapable ambiguity of humour as a concept, a point we return to later. Next, we attempt to unpack this paradoxical humour which is at once subversive, instrumental and, finally, ambivalent, by introducing the work of the phenomenologist Judith Butler, which helped us to make sense of the story of Keys that follows this introduction.

\section{Humour as subversion?}

A growing body of work has examined the use of humour in workplaces to critique and subvert dominant forms of power (see Westwood and Rhodes 2007 for a useful overview). Authors describe how humour, satire and cynicism can be used by, for example, lower status members of organizations to signal disenchantment (Collinson 2002), or to distance oneself from the control strategies employed by management (Collinson, 1988; Fleming and Sewell, 2002; Hodgson, 2005; Kunda, 1992). The idea is that the use of humour opens up a space for critique; the 'interruption of the everyday by jokes' often allows something that is 'routinely disallowed, to be seen or spoken of' (O’Doherty, 2007, p. 184). In this way, humour acts as something of an alternative space, an 'anti-rite' that shows up the sheer contingency of various social norms, including managerial control and other forms of domination in contemporary organizations (Critchley, 2007, p. 24).

A number of authors have lately drawn on Butler's idea of parody to show how aspects of organizations can be 'queered' by humorous forms of subversion (Hodgson, 2005; Kenny, 2009; Parker, 2002). Queering is based on Butler's rereading of the Lacanian Real, in which she shows how the laughter provoked by drag artists when parodying the notion of femaleness highlights the inescapable groundlessness of certain ways of thinking about gender in contemporary society. For Butler, such 'subversive laughter' flags up the ways in which 'the original, the authentic and the real are themselves constituted as effects' (Butler, 1990, p. 186). 
Examples of this include the UK TV programme The Office, which parodies management control (Tyler and Cohen, 2008) and the recent documentary film The Yes Men, which parodies the World Trade Organization and its control over global issues (Kenny, 2009).

In addition to parodying managerial control structures, studies have shown how humour can be used as a means to relativize power and poke fun at dominant and oppressive gender discourses in operation. Indeed, a central focus of Tyler and Cohen's (2008) study of The Office is on the programme's parodying of gender norms. Rhodes and Pullen (2007) explore the ways in which gendered stereotypes play out in the cartoon The Simpsons. They argue that the grotesque realist representation of, for example, Monty Burns' thin and sickly frame and Homer Simpson's excessive belly make us smile while showing up the fragility of masculine stereotypes. By representing and thus imitating an original, dominant conception of masculinity, The Simpsons 'defamiliariz(es) the mundane', makes it ridiculous and leaves it open to question (Westwood and Rhodes, 2007, p. 5). Johnston et al., (2007) discuss how humour can help to maintain particular gendered hegemonies, while exploring its potential for opening up other, alternative ways of knowing and of laughing. In summary then, humour is seen to have potential for subverting and critiquing dominant forms of power.

However, other studies from the field of organization research show that humour is frequently advocated as tool by which the very forms of power discussed above; gender norms and managerial control, are in fact sustained and reinforced. Bolton and Houlihan (2009) present an overview of different firms' attempts to use 'packaged fun' to engender a sense of happiness and belonging in employees $(2009$, p. 557). In other studies, humour is shown to be a useful means by which managers and leaders may influence their employees (Greatbatch and Clark, 2003). Cooper (2005) discusses the management of change within organizations, and argues that managers can use humour to convince employees of the benefit of proposed changes, 'if humour induces positive affect, the target will be influenced more easily' (2005, p. 773). Thus, she argues, humour should help to reinforce managerial control over change processes. Managers can also utilise humour to foster a coherent organizational identity. Kahn (1989) discusses how insider jokes and other forms of humour can be deployed to develop the boundaries necessary for establishing and maintaining shared norms; humour can help to separate those who belong from those who do not. 
Relevant to this article, Andriopoulos and Gotsi (2001) and Montuori (2003) argue that in the creative industries, humour can be fostered by management in order to promote creative work. Because, it is argued, creative thought is stimulated by the destabilization of order and the active dismantling of 'assumptions, givens, traditions, pushing boundaries and moving out of comfort zones', the frame-breaking potential of humour to highlight alternative ways of thinking can help to improve productivity, where the product involves the creation of new ideas (Montuori, 2003, p. 242). Thus, just as Critchley (2007) sees the frame-breaking potential of humour as a medium for critique, others view it as a means by which management can control aspects of work life including organizational change, culture and creative output (Bolton and Houlihan, 2009; Kahn, 1989; Montuori, 2003). Just as humour is seen to reinforce managerial prerogative, so it is with other forms of control such as norms of gender in operation (Johnston et al., 2007). Humour is frequently used to reinforce the dominance of patriarchal ways of knowing, as noted by Critchley (2007).

For these reasons, there is little to be said about what humour is in terms of its relation to control; the above discussion of the contrasts in the two strands in organization studies literature highlights the inescapable ambivalence of the concept (Collinson, 2002; Warren and Fineman, 2007). There is little that is inherently critical about humour, indeed, little is inherent in the notion at all. As Rhodes (2002) notes in his discussion of South Park's use of humour in critiquing global organizations such as Starbucks, what humour does is to enable the temporary reversal of particular hegemonies such as capitalism. He draws on Bakhtin's concept of carnival to show that while humour acts to continually relativize power and to suggest alternatives, it is finally ambivalent (Rhodes, 2002). Relevant to this article, Kuipers (2006) discusses the ambivalent role of online humour in challenging norms of ethnicity, arguing that Internet-based jokes using ethnic stereotypes can function to normalize these stereotypes in some cases, while simultaneously fanning the flames of moral outrage in others. Butler (1990) discusses this final ambivalence of humour, noting that parodic laughter can lose its critical edge when it becomes subsumed under the political structure it aims to critique. She draws on Foucault's idea that critique can, in fact, provide the comforting illusion that power is open to question and to alteration, when it is often simply a reinforcement of that power (Foucault, 1990). Specifically, Butler discusses the potential for parody to be commoditised, 'subversive performances always run the risk of becoming deadening clichés through their 
repetition and, most importantly, through their repetition within commodity culture where "subversion" carries market value' (1990, p. xxi). This idea of humour as both subversive and commercially saleable forms the focus of Parker's (2007) discussion of how workplace humour becomes commercialized by the manufacturers of office mugs and stickers that declare 'subversive' messages about employment and business. A further example is Kavanagh and O'Sullivan's (2007) examination of the sale of subversive humour in advertising campaigns. These ideas on the relation between organizational humour and control were helpful for us in making sense of life at Keys. Before introducing them, it is useful to return to Judith Butler's work and unpack relevant ideas in more depth.

\section{Wavering on the horizon: identity categories at work}

Gender theorist Judith Butler draws upon a number of ideas from psychoanalysis, feminist theory and poststructural theory in order to conceptualize the way in which norms such as gender, race and sexuality operate in contemporary society (Butler, 1990). In particular, she reworks the idea of the Lacanian Real in order to show how identities that draw upon these norms, for example, one's identity as 'woman', are neither static nor an essential attribute of the individual (Butler, 1990, 1993). Butler rejects the assumption that such positions are somehow natural and argues that, in fact, to assume such a natural identification is to conjure up the notion of some perfect example of the entity to which one refers. Such a perfect example cannot possibly exist, however, and so any reference to it is a reference to something that is alwaysalready moving away: 'gender parody reveals that the original identity after which gender fashions itself is an imitation without an origin' (1990, p. 175). If this ongoing construction of identity is taken to its full conclusion, one must reject the idea that there ever was some pure form of, for example, female gendered identity. In other words, the ongoing performance of identity merely involves a repeated citation of, or an 'aiming for' the idea of an ideal state, which doesn't actually exist: 'parody is of the very notion of an original; just as the psychoanalytic notion of gender identification is constituted by a fantasy of a fantasy' (Butler, 1990, p. 175). Identity is, for Butler, the politically inscribed pursuit of an ever-escaping ideal, a point made by organization theorists who have drawn upon her ideas to understand identification (Borgerson, 2005; Roberts, 2005). However, Butler argues, we are compelled to pursue. To be recognized as a valid human being we find ourselves subjected to 
particular, socially given norms of identification, and it is only by doing so that we escape the pain and violence associated with being left outside normative categories (Borgerson and Rehn, 2004; Butler, 1993). Thus, for Butler, identification and identity are inescapably political and central to the re-enactment of social norms (Butler, 2004).

There are two points of interest on the political potential of this theoretical approach to identification. Firstly, showing that a taken-for-granted identity is, finally, a 'fantasy of a fantasy', highlights its contingency and thus enables the problematization of given categories of identification, such as woman (Borgerson, 2005). Secondly, conceptualizing the ideal as a fantasy of a fantasy implies that within each 'risky enactment' lies the potential for subversion. While one is always 'doing' one's gender, the doing is not simple mimesis. The re-enactment of a given norm is inescapably complex and unstable, "'becoming' is no simple or continuous affair, but an uneasy practice of repetition' (Butler, 1997, p. 30). This unease comes from the Derridean notion of différance, the temporal difference between instances of a 'structure' that reinstates itself through time. The risk in the enactment also results from the inscription of a given norm by others. For example, gender is necessarily constituted differently in different historical and cultural contexts. Because 'gender intersects with racial, class, ethnic, sexual and regional modalities of discursively constituted identities', Butler finds that 'it becomes impossible to separate out "gender" from the political and cultural intersections in which it is invariably produced and maintained' (Butler, 1990, p. 6). Butler empirically illustrates this notion through an analysis of Nella Larson's novel, Passing, in which the protagonist is a mulatto woman who passes as white until the very end of the book, illustrating that the ways in which norms of race and ethnicity do not merely exist alongside gender norms, they are articulated through one another. In short, therefore, “"becoming" a particular identification is inscribed with instability and risk, a process that is 'compelled yet incomplete, wavering on the horizon of social being' (Butler, 1997, p. 30).

This wavering manifests itself in failures, deformity, difference and the 'possibility for diverse gestures and characteristics', that can disrupt and subvert the enactment of social norms (Borgerson, 2005, p. 71). Thus, in its very re-citation, the 'apparent ideal' at the heart of a social norm can 'elide, slide, alter (and) shift'. In Butler's work, this point supports her argument that, although contemporary conceptions of gender 
are part of a 'hegemonic, misogynist culture', their re-enactment contains the potential for them to not only be rendered denaturalised, but also to be mobilized in a new direction (1990, p. 176). It is these mobilizations that drive the kinds of subversive parodies described above. However, as was noted, subversion is not a given, 'parody by itself is not subversive' (1990, p. 176). It is only in certain, specific, contexts that one finds the kind of "parodic repetitions (that are) effectively disruptive, truly troubling' (Butler, 1990, p. 176).

\section{Observing humour at Keys}

Given these introductory ideas on humour and social norms, at this point we move to the story of Keys. The research engagement described here began when one of the authors was prompted to research the concept of creativity at work in the advertising sector. Keys was an obvious choice, having won a number of industry awards for creative excellence. The researcher became a participant observer, working as a creative consultant (Alvesson and Karreman, 2000; Bergstrom and Knights, 2006; Pratt, 2000). Most people working at Keys were young and male. As described above, work was quite informal, and socializing was encouraged through trips to the pub at lunchtime and after work. People wore funky clothes and discussed the latest music; in general, Keys was a typical advertising agency that considered itself to be at the cutting edge of cultural consumption and production (Nixon and Crewe, 2004).

E-mail lists provided a unique medium for sharing the latest ideas. After a while, it became clear that e-mail humour, in particular, was more than a simple distraction for staff at Keys; it formed a very important part of work there. This was clear from the amount of time spent trawling the Internet for newer and funnier jokes, pictures and online videos, in addition to the lengthy discussions that occurred after the sending of such mails. This centrality is exemplified in the series of photographs in Figure 1. These images were inspired by an e-mail sent out one Friday, with the subject line: 'It's Friday + Photoshop'. The e-mail had two photographs attached: one of the finance director and another of the human resources director. This simple call to action was quickly taken up across the office, with graphics software used to transpose the faces of these colleagues onto a myriad of backgrounds. A flurry of responses came back across the e-mail lists as directors and staff alike created and sent around new images. 
In total, 13 separate transposed images were sent back to the mailing list, the creation of which took up much of Friday afternoon. Eventually, the human resources manager responded from home, as she had taken a day off due to illness: 'Yoos lot are a bunch of $b^{* *} \operatorname{trds}$ - here I am on my death bed and this is what happens! P.S. I'm quite liking the Saturday night fever one though ...' In general, funny e-mail lists were 'serious business' at Keys. This interaction highlights how e-mail humour was central to life at the organization, regardless of one's position. It was used not only by creatives, those staff members responsible for the design and development of ideas, but also by senior management, campaign planners and accounting staff.

The following account is based upon over 655 'humorous' e-mails that were collected over a four-month period. While it is difficult to ascertain the 'funnyness' of a given joke, the nature of the data collected provided us with an interesting indication; a funny or popular e-mail will tend to prompt replies via e-mail, depending upon peoples' reaction to it. The jokes chosen for analysis here either prompted significant response of this nature, or alternatively, were reported to yield a significant verbal response in the participant observation field notes prepared during the study (Cooper, 2008). Given this, the analysis of our data involved reading and re-reading the subset of e-mails, isolating particular themes and iterating between these themes and relevant literature (Brewis and Linstead, 2000). In addition, the in-depth engagement of the researcher at this organization enabled a deeper contextual understanding of how the humour being described played out in this organization over time. The story of Keys that follows describes the life of the particular flavour of email humour found here, one in which political incorrectness and constant newness were key features.

\section{Porn, nationality and power: jokes at Keys}

At Keys, humour acted to simultaneously subvert and uphold particular, dominant ways of knowing within the organization. This paradox is illustrated by drawing on some of the humorous e-mails gathered during the study. In addition, it appeared that humour generated something of an excess, beyond the control and resistance dualism. Humour appeared to be something more.

As mentioned above, humour was part of the management and employee relationship, albeit in a complex way. It might be assumed that the informal teasing of managers, via publicly exchanged e-mail lists, posed a threat to the authority of 
Keys's managers. Indeed, any overt display of this authority would quickly be parodied on the e-mail lists by the rest of the organization. This was clear when, for example, the creative director, one of the most senior people in the organization, sent an e-mail that asked for the downstairs kitchen to be kept clean. He asked people to place dirty dishes in the dishwasher. This simple request prompted a number of e-mail responses; someone replied that the same holds for the upstairs kitchen, which was followed by a developer replying that the same goes for his kitchen at home. Another developer wrote:

Subject: RE: Same goes for my kitchen ... also if someone would like to come and finish building my kitchen (still no working tops or cupboards or sink) then I'd be mega appreciative, oh and then I'd have surfaces to clean and weekends free ... thanking muchly.

Thus, a simple request from management was recirculated and parodied, defusing its seriousness. Incidents like this were frequent and, drawing on aspects of the literature presented above, may lead one to conclude that they represented a subversion of management control (Kunda, 1992). However, the story at Keys was more complex. Senior managers themselves regularly participated in using the e-mail lists for sending around humorous e-mails; the design and production directors were among those most active, contributing 8 per cent of the humorous e-mails sent between them (and representing only 4 per cent of the staff). As an example, in preparation for a weekly staff meeting one senior manager wrote:

Please try to furnish me with things to say at the weekly staff meeting or stare in horror as I blunder on in front of you for yet another week ... 10.45 round the downstairs meeting area, cheers, MD.

The nine board members, who made up a fifth of the staff, sent out almost a fifth of the total number of humorous e-mails collected. Interestingly, this ethos of being funny was by no means counterproductive in terms of the goals of the organization and management's prerogative in generating profit. What Cooper (2005) describes as the sharing of visual and interactive humour, via e-mail, was a useful activity, particularly given that a proportion of these e-mails featured recent creations from competing advertising agencies. Using the e-mail lists to demonstrate ones' imagination, creativity and general sense of humour was often tantamount to carrying out market research on behalf of the firm, research which is then passed along to one's colleagues via the joke e-mails being studied here (Montuori, 2003). In 
addition, as noted above, the frame-breaking role of humour in generating ideas is valuable to creative industries such as advertising (Montuori, 2003). In addition, online porn sites were recognized as being useful for observing and learning about latest innovations in web technology and so were helpful in developing client proposals. At Keys therefore, playing online games (see Figure 2), surfing the Internet for funny ads, and other aspects of work life that are often considered by more traditional organizations as mere time wasting (Sharma and Gupta, 2004) were not only encouraged, but frequently carried out by management itself. In summary then, while humour was used to undermine authority it was also accepted and used by those in authority (Collinson, 2002). The relation between humour and control was complex and ambivalent, as was the relation between humour and gender, discussed next.

Figure 2 around here

In terms of the enactment of gender stereotypes at Keys, e-mail humour played an important role. As mentioned previously, aspects of life that would traditionally be seen as taboo in work organizations, in particular in written communications by staff members, were frequently parodied. These aspects include religion, sexuality, homelessness, drugs, alcohol abuse and the personal lives of Keys employees and suppliers. The result of this was that much of the humour that appeared on the Keys mailing list could be interpreted as offensive by normal standards (Kuipers, 2006). In analysing the data, we authors disagreed on whether or not many of these jokes could be considered offensive, which indicates the difficulty in deciding normal standards of political correctness. Examples of gendered humour include a link sent by one illustrator to a 'G.I. Joe Erotica Fan Fiction Archive' where fans wrote their own G.I. Joe stories with erotic endings. In another example, a link to a company which sells 'fake vagina g-strings with peeholes' was sent around. An illustrator forwarded an email with that featured the web address: www.whorepresents.com, and commented upon how disappointing it was that this merely led to an agency that represents actors. In these ways, women were sexualized and this aspect was parodied and made fun of. In addition, male gender stereotypes, including that of a homeless man and a new father, were mocked. For example, a Christmas card sent around by the production director showed a cartoon version of a well-known Christmas carol. In the cartoon Santa Claus was replaced by Tramp-o-Claus, who bellowed a song to the tune of 'Santa Claus is Coming to Town' about the various disgusting ways in which he planned to interfere with the traditional family Christmas festivities. This is shown in 
Figure 3. Instead of mince pies, Tramp-o-Claus asks the waiting children to leave out porn magazines and cigarettes on Christmas Eve.

Insert Figure 3 around here

Santa Claus is thus reworked as a dirty, homeless man and this stereotype is mocked in doing so. Traditional father roles were parodied; when one of the design directors became a father, an illustrator wrote the following e-mail to all employees: 'Suzuki scooter + helmet hardly used. one careful owner. 500EUR. Ono'. The implication was that impending fatherhood would render the design director old and boring.

Gender humour was often inscribed by mocking of other aspects of identity, including nationality. Excerpts from an episode of a TV cartoon series which made fun of Irish women for typically praying and having lots of children, shown in Figure 4, were sent around by the most junior production employee, despite the fact that one of the design directors was Irish.

\section{Insert Figure 4 around here}

This form of humour was turned around on the researcher, a German, when an email was sent around featuring a picture of him with a collection of porn magazines which had been Photoshopped into his hands; making fun of the stereotypical relation of Germans to porn. Similarly, on announcing his move to The Netherlands, the researcher was the butt of a flurry of e-mail jokes, culminating in the goodbye e-mail which announced that the researcher was moving on to a life of prostitutes. These examples highlight the ways in which particular gender stereotypes: Irish mothers, Dutch prostitutes and male German porn consumers were articulated through national stereotypes in their humorous parodying by staff at Keys (Butler, 1990; 1993).

Politically incorrect humour reached such levels at one point that the author of an e-mail whose content was not smutty, offensive or of dubious taste, excused himself by adding 'some good clean fun' in the subject line. In addition, making fun of individual staff members had become part of using the e-mail lists. Being funny appeared more important than showing respect or sensitivity for your co-workers and peers, even in accordance with traditional social norms. However, there were limits to this, as was illustrated when the managing director put a stop to offensive humour directed at his wife. The tradition in Keys, when a staff member had a birthday, was for one of the illustrators to create a digital birthday card and send a link around by email so that everyone could write a birthday wish on it. Working on such a card one 
day, the illustrator came across an 'alternative' dictionary of peoples' names. He found that the managing director's wife's name was defined as a person who liked to have group sex with random people. This was duly written on the birthday card. It was not known what passed between the managing director and this illustrator but he never designed another card. In this case, therefore, it appeared that the operation of humour was, in addition to being inscribed by norms of gender and nationality, inextricable from questions of power and status in the organization. This adds to the complexities of the way in which humour was enacted at Keys.

Interestingly however, in the days and months that followed, the incident remained alive in the e-mail jokes that were sent around on the mailing lists. In one case, images of the chastised illustrator were distributed, in which he was shown in a new profession as a T-shirt designer, the implication being that he was shortly to be fired. Another e-mail showed an online diagram of how he might industrialize these birthday cards, again in his future, post-Keys career. Other jokes discussed who the next candidate for the role of designing offensive birthday cards might be. This continuous movement of humour, even beyond the attempts by the managing director to stop it, indicates that in fact, humour was somehow beyond a consideration of control versus resistance; humour appeared to generate something of an excess, a spilling over and out of these categories. Likewise, even where humour was inscribed by categories of nationality and gender, as discussed above, even this necessitated a continual movement. At one point, a spate of e-mails were sent around that were considered sexist, such as those described above. These included one from the planning director entitled, 'Fun for the boys'. Two new e-mail lists were created: one called ‘boys@keys.com' and a second entitled 'girls@keys.com'. These were for the purpose of avoiding an audience that might find the content of such e-mails offensive. Interestingly, however, the boys-only e-mail list was rarely used and eventually became obsolete (the researcher was not party to the girls-only list). Both examples indicate that something beyond traditional conceptions of humour was at work at Keys; an alternative norm, one of continuous movement, appeared central.

\section{As long as it's new ...}

As mentioned above, a norm of newness, in relation to humour, appeared to persist in Keys. The almost dogmatic importance to newness ascribed by staff members stands in interesting contrast to the laid back, joky atmosphere of the organization. This was 
implied above but it is best illustrated in the description of a conflict that arose one day that occurred as a result of recent activity on the e-mailing lists. It is important to note that conflict at Keys, in the context of the e-mailing lists, was rare. None of the examples presented so far led to a serious argument between Keys staff members; both e-mail responses and verbal discussion around these e-mails were joking and light-hearted. Where conflict did arise, it involved people who were perceived to be sending old jokes that had been seen before by the team. These accusations tended to be levelled at members of the planning team. One day, Keys' information technology manager sent an e-mail message describing a new spam filter programme he was working on. This would enable the blocking of unwanted e-mail from outside Keys, for example, unsolicited advertisements and notices from unknown sources. In planning this filter he asked everyone in the organization to send him a list of e-mail addresses from which they have received spam in the past. One of the design directors proposed to filter the addresses of the planners, indicating that he considered their 'humorous' e-mails to be as interesting and funny as spam. This led to a number of conversations in the office in which the planners were discussed as providing most of the old and unfunny mails. JP, a junior planner, was really upset about this, which he made clear in conversations with his colleagues. Furthermore, in the following days he responded to almost every humorous e-mail that was sent by saying that it was rubbish. Both he and his planner colleague also began adding sentences such as 'I don't know whether this has been sent around before', to even ordinary work-related e-mails. However, this incident did not stop the planners from continuing to send humorous e-mails. In fact two days later, JP sent an e-mail about a guy who called himself 'bloodninja' and made fun of other people by chatting with them in online sex forums. The directors and developers who had previously mocked him responded that this was so funny that they considered JP to have 'totally redeemed himself'. One of the creative team could not resist, sending another e-mail, agreeing that the bloodninja e-mail was very funny, even 'two years after it first came around)'. This series of email interactions was continually referred to in the days and weeks afterward. For example, one staff member sent around some jokes, acknowledging that they were old, but saying that this was okay, since the planners were not at work that day.

In summary, it appeared that in Keys being funny and being new was more important than maintaining a hierarchical status quo of behaviour, displaying sensitivity for one's colleagues or even than staying within socially accepted 
boundaries of decency. The traditional boundaries of social niceties did not apply; it was generally acceptable to make fun of one's colleagues' personal situations, to be 'disgusting' or politically incorrect, as long as the content of the e-mail was new. This shows there was an interesting paradox within this performative re-enactment of humour as an organizational norm. While on the one hand there were few a priori restrictions on what content might be considered funny, on the other hand, perhaps counter to initial impressions, there were in fact strict implicit limitations on the kinds of humour that could be sent around. Sharing old, already-seen humour was taboo: to do so would involve the sender being derided and publicly mocked. In the example above, JP transgressed the norm of newness and had been publicly chastised via the email list upon which he had continually distributed old jokes. Having been sanctioned in this way, he was then forgiven and brought back into the fold, the implication being that he had learned his lesson. In summary therefore, e-mail jokes were expected to always be moving towards something different and unforeseen; they were expected to be new.

\section{Discussing humour at Keys}

At Keys, the specific flavour of politically incorrect humour operated as something of a complex norm, inscribed by managerial control and gender (Butler, 1993).

Nationality also played a role. Interestingly, these norms are in turn inextricably linked to e-mail humour, in terms of the ways in which they are enacted in day-to-day life at Keys. Conceptions of gender, nationality and power are performed through email humour.

Returning to the literature on control and subversion with regards to e-mail humour therefore, given our story of the ongoing play of the norm of politically incorrect humour, we concur with the view that humour has something of a role to play in opening up aspects of the status quo and control relationships for questioning and for critique (Hochschild, 1983; Hodgson, 2005; Kenny, 2009). This was apparent when emails from management that asked staff to clean the kitchen were replied to in a joking manner, and when the managing director's wife was made fun of. However, these incidents indicate that humour is more than a means by which existing control structures are satirized and resisted. Humour at Keys was, finally, ambivalent in its relation to control and subversion (Collinson, 2002; Hodgson, 2005; Kavanagh and O'Sullivan, 2007; O’Doherty, 2007). This may be a result of the particular context of 
Keys. Firstly, the teasing between staff and management is perhaps understandable, given that Keys is a young organization and the elevation of many of the directors described here to the status of manager is a relatively recent occurrence. In addition, given the creative nature of Keys' work, the importance of e-mail humour in opening up of new ways of thinking was recognized by managers as important in developing this creativity (Bolton and Houlihan, 2009). Thus, at Keys, “"subversion” carries market value' (Butler, 1990, p. xxi).

We have seen that although the role of humour in control, subversion and the operations of norms of gender and nationality appeared to be ambivalent and complex, the norm of continuously driving towards newness, towards the next laugh, persisted. As was shown above, even when the managing director's reaction to the group sex joke put a stop to the birthday card tradition, the incident itself became a source of new humour; it remained alive and proliferated beyond the occasion itself. Similarly, even where sexist jokes prompted the creation of a boys-only e-mailing list, this list was used a few times, fizzled out and died off. These examples have parallels with the aftermath of the public chastisement of the person found guilty of sending old humour around, described above. In the weeks afterwards, this incident was itself taken up by e-mail senders as a source of fun (including the culprit, who made fun of himself). In all cases described here, the humour was continuously moving and shifting, using whatever was new, the latest situation, in order to make fun. The question remains as to how we might further unpack this newness.

Butler's re-reading of the Lacanian Real shows how processes of normative reenactment hold potential for showing the final 'groundlessness of the ground' of taken-for-granted aspects of social life. Her introduction of ideas of différance into our understanding of such re-enactments and conception of their final inscription by a myriad of other identifications shows the potential for subverting the ways in which the ground is re-enacted (Butler, 1990, p. 179). Drawing on this difference, this 'unknowingness' in Butler's concept of normative reproduction, it is the element of chance in each citation of the norm, this unpredictable shift in the re-citation of an accepted way of knowing the world, that produces this compelling 'newness' and that makes the e-mail funny. With any citation the action itself changes slightly the meaning of the cited and thus, humour drifts. This drift can be seen in the example given in Figure 1. The element of chance in the performative citation of humour means that it is never possible to determine in advance whether something will or will 
not be funny to the rest of the organization, since humour itself is a shifting concept. Importantly, this drift in humour as a quest for newness implies that as soon as the extreme becomes the norm, the 'carnival' (Rhodes, 2002) may be turned on its head and itself become the target of parody, as was observed above. Following Butler, we therefore argue that the humour we encountered is not something stable, that can be frozen, captured or spoken about: rather, it is always-already moving away from definition. Drawing on Butler's conception of social entities as nonessential and fragile, we thus see humour as a 'nicely impossible' ideal: an entity that is always in flux (Critchley, 2007, p. 19).

This approach forms a contribution to contemporary debates on workplace humour. As Bolton and Houlihan argue, questions must be asked regarding 'what is humour at work, and what does it do?' (2009, p. 557, emphasis added). In this article we argue for moving away from a static conception of humour and questions about what it is. Instead, at Keys, humour represents something of an ongoing quest for newness that always remains unfilled, an 'always becoming' that continually escapes apprehension (Butler, 1990). Finally, while some studies have focused on the growing ubiquity of e-mail use at work (Sharma and Gupta, 2004; Tassabehji and Vakola, 2005) and the many ways in which it can be used in such settings (see, for example, Whittaker et al., 2005; van den Hooff et al., 2004; Weber, 2004), as yet there is a dearth of in-depth, participant observation studies on the use of humour in organizational e-mail lists. It is therefore hoped that this article will make a further contribution to this topic. In concluding, we return to the political potential for humour to subvert given forms of power and ask: what next?

\section{Concluding remarks}

As discussed above, the potential for norms to be cited differently over time opens up a space for critique and for subversion. Indeed, at Keys, it is clear that the image of the firm is one that prides itself on questioning the status quo, playing with particular norms from its position at the cutting edge of cultural production. Such an organization might therefore appear to be one in which critique and subversion would play a key role in the ways in which interactions such as e-mail humour play out. Drawing on the idea of humour as a moving fantasy of fantasy, highlighting its temporal, enacted nature but also showing how it is finally, impossible to capture, we might expect an opening up of the norm that is politically incorrect humour at Keys. 
Perhaps the humour on the e-mail lists at Keys would provide a means by which employees could lay hold of dominant norms in the space opened up by parodic laughter, such as the gender stereotypes discussed previously, and, perhaps, show how things can be perceived differently. In other words, perhaps the demand for newness itself, which contains within it the requirement to drift and to move forward, holds the potential for trouble. However, as Butler notes, we require a specific context before subversion through the use of humour and parody become 'truly troubling' in terms of their ability to upset the norm. Indeed, given the harnessing of subversion and humour at Keys by the particular requirements of profit, it could be argued that the only truly troubling aspect of humour at this organization was its reinforcement of a particular, offensive, generic and arrogant form of politically incorrect humour. Thus, the parodying of stereotypes in Keys may simply act to maintain particular, oppressive 'instruments of cultural hegemony' (Butler, 1990, p. 176). The unknowingness in the repetition, however, means that the potential for subversion always remains.

\section{References}

Alvesson, M. and Karreman, D. (2000) Varieties of discourse: on the study of organisations through discourse analysis. Human Relations, 53,9, 1125-49.

Andriopoulos, C. and Gotsi, M. (2001) 'Living' the corporate identity: case studies from the creative industry. Corporate Reputation Review, 4,2, 144-54.

Bergstrom, O. and Knights, D. (2006) Organizational discourse and subjectivity: subjectification during processes of recruitment. Organization 59,3, 351-77.

Bolton, S. and Houlihan, M. (2009) Are we having fun yet? A consideration of workplace fun and engagement. Employee Relations, 31,6, 556-68.

Borgerson, J. (2005) Judith Butler: on organizing subjectivities. Sociological Review, $53,1,63-79$.

Borgerson, J. and Rehn, A. (2004) General economy and productive dualisms. Gender, Work \& Organization, 11,4, 455-74.

Brewis, J. and Linstead, S. (2000) The worst thing is the screwing: consumption and the management of identity in sex work. Gender, Work \& Organization, 7,2, 8497.

Butler, J. (1990) Gender Trouble: Feminism and the Subversion of Identity. London: Routledge. 
Butler, J. (1993) Bodies That Matter: On the Discursive Limits of 'Sex'. London: Routledge.

Butler, J. (1997) The Psychic Life of Power: Theories in Subjection. London: Routledge.

Butler, J. (2004) Undoing Gender. London: Routledge

Collinson, D. (1988) Engineering humour: masculinity, joking and conflict in shop floor relations. Organization Studies, 9,2, 181-99.

Collinson, D. (2002) Managing humour. Journal of Management Studies, 39,2, 26989.

Cooper, C. (2005) Just joking around? Employee humor expression as an ingratiatory behavior. Academy of Management Review, 30,4, 765-76.

Cooper, C. (2008) Elucidating the bonds of workplace humor: a relational process model. Human Relations, 61,8, 1087-115.

Coser, R.L. (1959) Some Social functions of laughter: a study of humor in a hospital setting. Human Relations, 12,2, 171-87.

Critchley, S. (2007) Humour as practically enacted theory, or, why critics should tell more jokes. In Westwood, R. and Rhodes, C. (eds) Humour, Work and Organization, pp. 17-33.Abingdon: Routledge.

Fineman, S. (2003) Understanding Emotion at Work. London: Sage.

Fleming, P. and Sewell, G. (2002) Looking for the good soldier? Svejk: alternative modalities of resistance in the contemporary workplace. Sociology, 36,4, 857-73.

Foucault, M. (1990) The History of Sexuality: Volume 1, An Introduction. London: Penguin.

Greatbatch, D. and Clark, T. (2003) Displaying group cohesiveness: humour and laughter in the public lectures of management gurus. Human Relations, 56,12, $1515-44$.

Hochschild, A. (1983) The Managed Heart: Commercialization of Human Feeling. Berkeley, CA: University of California Press.

Hodgson, D. (2005) Putting on a professional performance: performativity, subversion and project management. Organization, 12,1, 51-68.

Johnston, A., Mumby, D. K. and Westwood, B. (2007) Representing the unrepresentable: gender, humour and organization. In Westwood, R. and Rhodes, C. (eds) Humour, Work and Organization, pp. 113-39. Abingdon: Routledge, 
Kahn, W.H. (1989) Toward a sense of organizational humor: implications for organizational diagnosis and change. The Journal of Applied Behavioral Science, $25,1,45-63$.

Kavanagh, D. and O'Sullivan, D. (2007) Advertising: the organizational production of humour. In Westwood, R. and Rhodes, C. (eds) Humour, Work and Organization, pp. 235-49. Abingdon: Routledge.

Kenny, K. (2009) The performative surprise: parody, documentary and critique. Culture and Organization, 15,2, 221-35.

Kuipers, G. (2006) The social construction of digital danger: debating, defusing and inflating the moral dangers of online humor and pornography in The Netherlands and the United States. New Media and Society, 8,3, 379-400.

Kunda, G. (1992) Engineering Culture: Control and Commitment in a High-Tech Corporation. Philadelphia, PA: Temple University Press.

Montuori, A. (2003) The complexity of improvisation and the improvisation of complexity: social science, art and creativity. Human Relations, 56,2, 237-55.

Nixon, S. and Crewe, B. (2004) Pleasure at work? Gender, consumption and workbased identities in the creative industries. Consumption, Markets and Culture, 7,2, $129-47$.

O'Doherty, D. (2007) Heidegger's unfunny and the academic text: organization analysis on the blink. In Westwood, R. and Rhodes, C. (eds) Humour, Work and Organization, pp. 180-204. Abingdon: Routledge.

Parker, M. (2002) Queering management and organisation. Gender, Work \& Organisation, 9,2, 146-66.

Parker, M. (2007) 'The Little Book of Management Bollocks' and the culture of organization. In R. Westwood and C. Rhodes (eds) Humour, Work and Organization, pp. 77-92. Abingdon: Routledge

Pratt, M. (2000) The good, the bad and the ambivalent: managing identification among Amway distributors. Administrative Science Quarterly, 45,xx, 456-93.

Rhodes, C. (2002) Coffee and the business of pleasure: the case of Harbucks vs. Mr. Tweek. Culture and Organization, 8, 4, 293-306.

Rhodes, C. and Pullen, A. (2007) Representing the d'other: the grotesque body and masculinity at work in The Simpsons. In Westwood, R. and Rhodes, C. (eds) Humour, Work and Organization, pp. 161-80. Abingdon: Routledge, 
Roberts, J. (2005) The power of the 'imaginary' in disciplinary processes. Organization, 12,5, 619-42.

Sharma, S. and Gupta, J. (2004) Improving workers' productivity and reducing internet abuse. The Journal of Computer Information Systems, 44, 2, 74-78.

Tassabehji, R. and Vakola, M. (2005) Business e-mail: the killer impact.

Communications of the ACM, 48, 11,xx, 64-70.

Tyler, M. and Cohen, L. (2008) Management in/as comic relief: queer theory and gender performativity in The Office. Gender, Work \& Organization, 15,2, 113-32.

Van den Hooff, B., Groot, J., and de Jonge, S. (2004) Situational influences on the use of communication technologies: a meta-analysis and exploratory study. Journal of Business Communication, 41,2, 4-27.

Warren, S. and Fineman, S. (2007) Don't get me wrong, it's fun here, but ...: ambivalence and paradox in a 'fun' working environment. Westwood, R. and Rhodes, C. (eds) Humour, Work and Organization, pp. 92-113. Abingdon: Routledge.

Weber, R. (2004) Editor's comments. MIS Quarterly, 28,3, iii-xii.

Westwood, R. and Rhodes, C. (2007) Humour and the study of organizations. In R. Westwood and C. Rhodes (eds) Humour, Work and Organization, pp. 1-15. Abingdon: Routledge.

Whittaker, S., Belotti, V., and Moody, P. (2005) Revisting and reinventing e-mail. Human-Computer Interaction, 20,1-2, 1-10. 


\section{Figures}

\section{Figure 1}

Excerpts from 'it's Friday + photoshop'

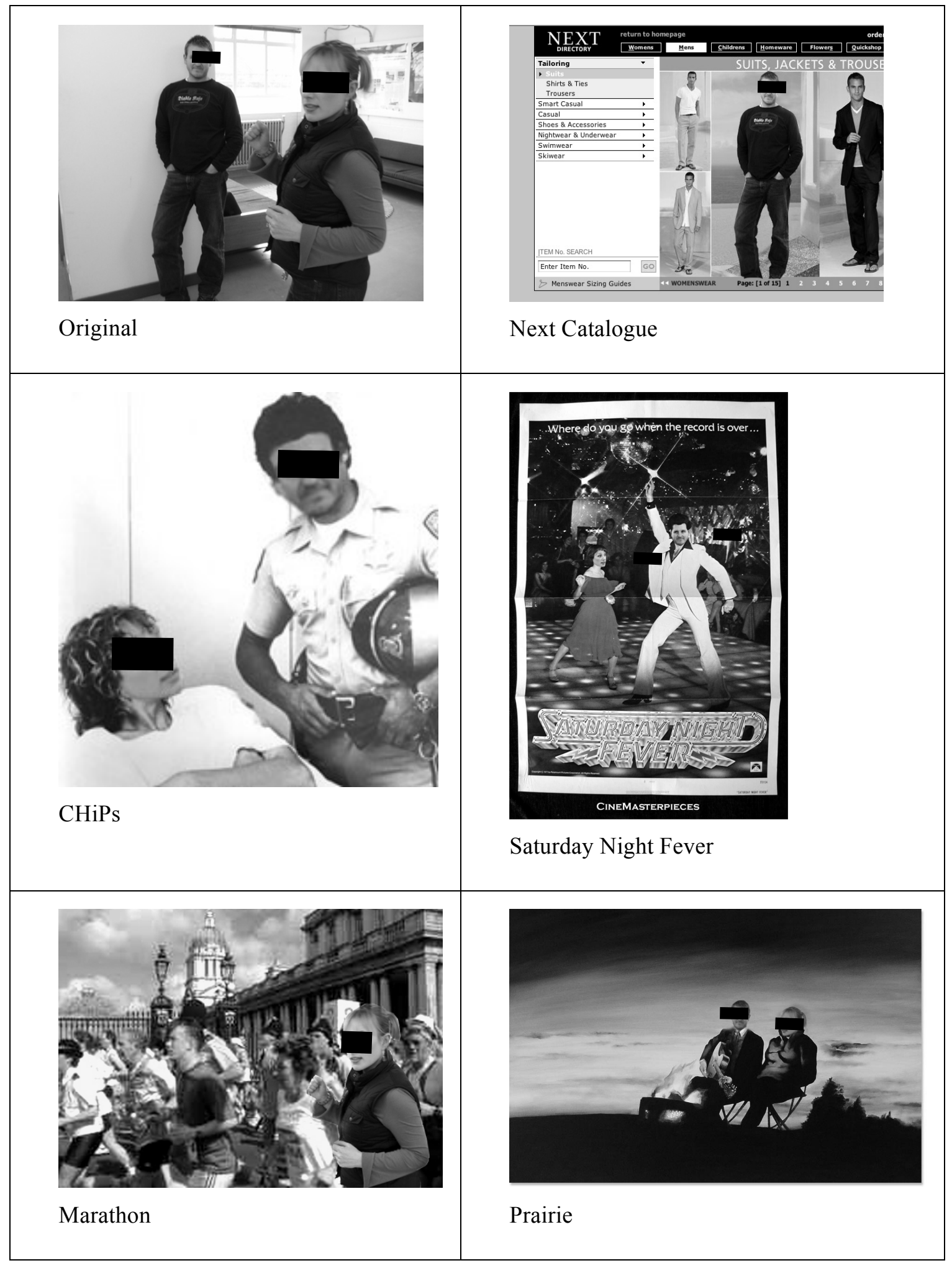


Figure 2

Online Game - Highscore

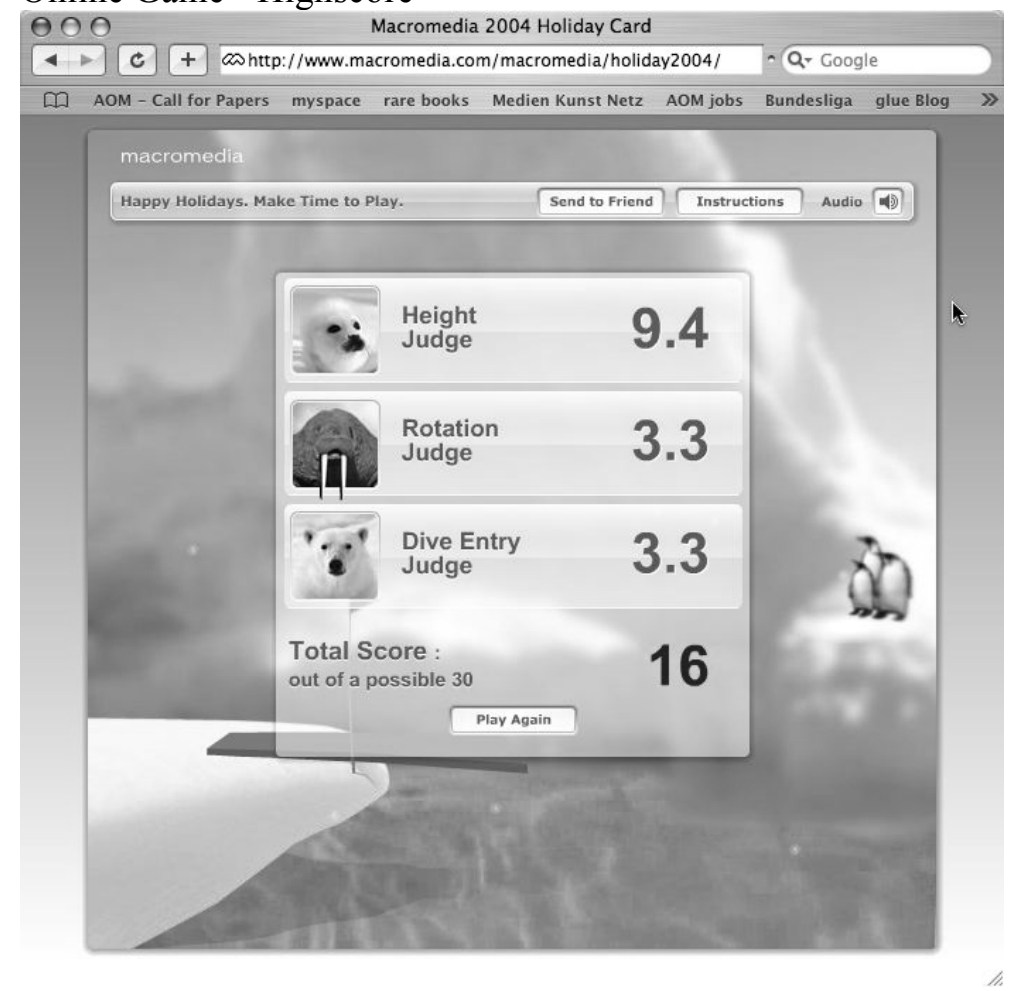


Figure 3

Tramp-O-Claus

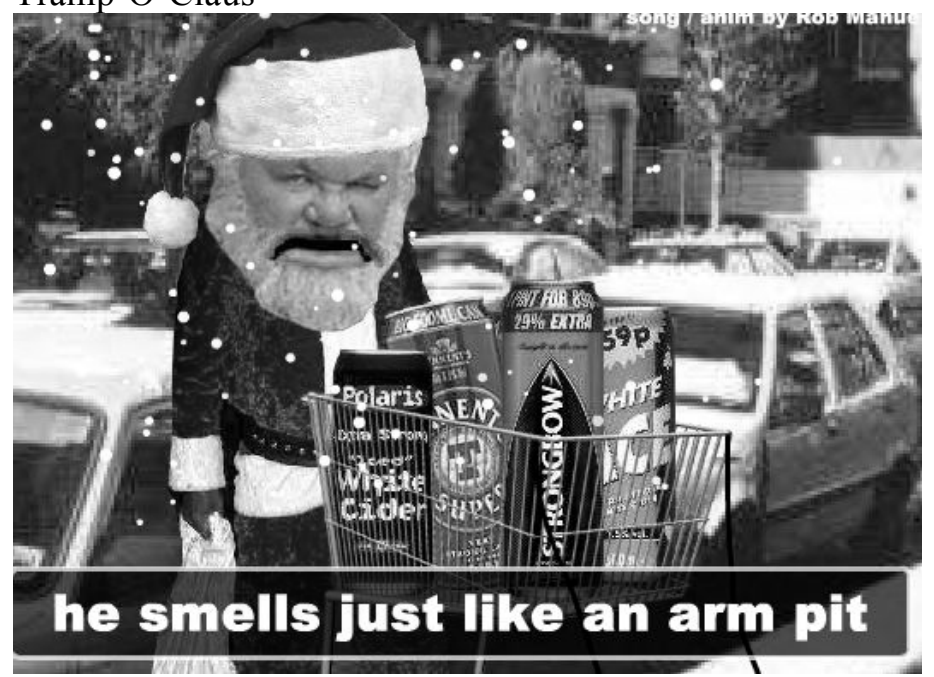

Figure 4

Making Fun of Nationalities

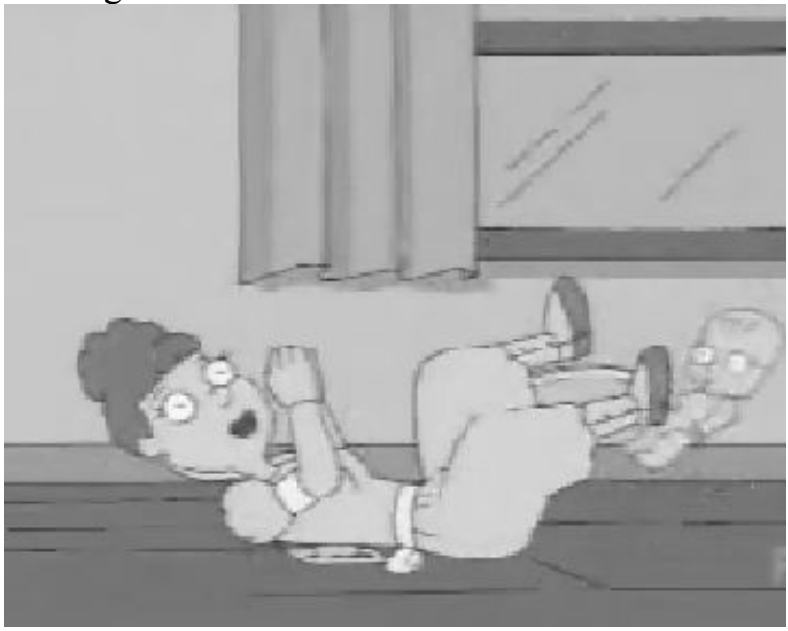

